\title{
Health Technology and U.S. Medicare Policy in the Late 20th Century
}

\author{
Randall E. Basham \\ The University of Texas at Arlington
}

\begin{abstract}
Much of the history of the American Social Welfare movement has been directed to the identification and development of entitlement programs needed to strengthen the health and economy of even the neediest members of the society. The emergence of health technologies have precipitated and supported policy advances. The Medicare Act (Title XVIII the United States Social Security Act of 1935) as such an entitlement program, was originally directed to resolving the health coverage concerns of the elderly without families or finances to afford coverage. The program entered crises periods over rising costs and continuity of funding concerns. Many have been assisted, in the U.S., in addition to the aged population, by the development of Medicare entitlements. These entitlements have emerged during periods of social need often accompanied by health technology or service delivery innovation. The program benefits more than its constituents and contributes to the health of the overall society. This paper will provide both a historical overview of the conflicts and uncertainties weathered by the Medicare Act in the later quarter of the $20^{\text {th }}$ Century in the U.S. (United States of America). The paper will also explore the implications of changes in the technology of federal and state funding mechanisms along with demographic changes that offered the greatest challenges to the continuation of the Medicare Act as a mainstay of stable health coverage to millions of needy Americans, into the $21^{\text {st }}$ century.
\end{abstract}

Keywords: health technology, U.S. medicare policy, 20th century

\section{Introduction}

Ushering in of the new millennium has brought sweeping geopolitical changes and socio economic responses to our nation and to our world. In the years leading up to the change from the past millennium to the initial decade of the new millennium, global conflict and uncertainty and national reactions to rapidly changing health service technology have been unparalleled. International conflict and human suffering have become pandemic. New violence and new disease and new economic strife have served to ruin the relatively stable health and cultures of large portions of the world of the last millennium. These changes occurred despite the best intentions of global leaders and service delivery planners and the dramatic improvements in the capacity of developed nations to grow and deliver large inventories of sustaining food and water, to rapidly access information and technology to improve health services and health service delivery.

A 1998, U.S. Census Bureau Current Population Survey indicated that approximately 35 to 36 million recipients, at that time, were covered by Medicare Health Insurance, which represented over 13 percent of all persons surveyed further, an estimated 3 to 4 million Medicare recipients that were not considered elderly. In

Randall E. Basham, Ph.D., Doctor of Social Work, The University of Texas at Arlington. 
most available survey information of the period, the poor represented a larger proportion of the Medicare recipients (Bureau, 1998).

Medicare had been fraught with change and uncertainty almost since passage of the program in 1965. A combination of increasing demands from vocal and needy constituencies has resulted in continuous expansion of critical health care services, along with clinical and technical innovations, which held the promise of reduced costs. The unanticipated costs of providing these services however resulted in tighter cost containment efforts from oversight authorities. However, a series of funding and economic crisis in the health funding sector of state and federal government resulted in the substantial threats to the continuity of the program, over time as compared to its original conception. The ideals of the original program were best summed up by President Lyndon Baines Johnson at the signing of the Medicare Act.

No longer will older Americans be denied the healing miracle of modern medicine.

No longer will illness crush and destroy the savings they have so carefully put away

over a lifetime so that they might enjoy dignity in their later years. No longer will

young families see their own incomes, and their own hopes, eaten away simply

because they are carrying out their deep moral obligations (President Lyndon B. Johnson, at the signing of the Medicare legislation. July 1965: Cassel, Besdine, \& Siegel, 1999, p. 118)

These changes have contributed to an exponential rise of health service and delivery costs, changes in usage of services, increased accountability considerations, and changes in the types of service programs that are needed for differing consumers. Service provider groups have also changed with respect to which groups are supported in efforts to deliver health care. Competing interest groups vie for limited funding to gain higher quality and quality of care and services. Therefore, these changes have led to politically charged competition for comprehensive care among the most vocal.

\section{The Medicare of the Last Millennium}

During 1965 the United States Social Security Act of 1935 was amended to include an entitlement program designated as Title XVIII and known as Medicare, or "Health Insurance for the Aged and Disabled" (Social Security Administration, 1998b). This program supplemented the already existing retirement and disability benefits that had been developed through the previous titles of the legislation (Noridian Mutual Insurance, 1999).

The Medicare program opted to cover a single group of citizens who were over the age of 65 (Social Security Administration, 1998a). Other groups were eventually included such as those who were entitled to disability benefits for 24 months or longer, individuals suffering from end stage renal disease, and those eligible but not covered and wishing to purchase Medicare (Social Security Administration, 1998a).

Medicare was formally implemented in 1966 and contained two forms of insurance. One program consisted specifically of hospital insurance coverage. This coverage option was designated as "Part A" or HI (Hospital Insurance). The other program known as SMI (supplementary medical insurance), or "Part B" was designed to cover various approved primary care and outpatient services for recipients. Part B included voluntary coverage upon payment of the "SMI" premium (Noridian Mutual Insurance, 1999). These covered services included physician services, outpatient clinic and hospital services, and home health services (Social Security Administration, 1998a). 


\section{Changes in Medicare}

The first major additions to covered groups were legislated in 1972. At that time both disabled individuals and those with end stage renal disease under the age of 65 were entitled to enroll in "Part A" coverage and "Part B" coverage. Additionally, supplemental "Part B" benefits were expanded to include the services of chiropractors, speech pathologists, and some limited physical therapy services. Since this expansion, most revisions or broadening of coverage have involved "Part B" benefits only (Social Security Administration, 1998a).

Medicare Part A coverage has remained the core portion of entitlement available to most beneficiaries. Types of institutional services have been stable, but reimbursement criteria for care have become more restrictive (Noridian Mutual Insurance, 1999). A number of cost containment efforts over the years have eroded the availability of some services for segments of beneficiary populations.

Hospital insurance (HI) has not been expanded since 1972 (Noridian Mutual Insurance, 1999). Outpatient services and benefits have been added throughout the history of Medicare. Benefits have some additional restrictions on eligibility. For example, hospital services are reviewed to determine if they were medically necessary and are reimbursed based on diagnosis related groups (DRG's) criteria. Reimbursement criteria depend upon similar diagnoses and are paid as a lump sum. Coverage includes all charges for hospitalization, services, supplies, and procedures.

Eligibility criteria must also be met for coverage of skilled nursing facility (SNF), home health (HHA), and hospice care. Hospice care was not added as a benefit until 1983 and requires the patient sign a waiver of hospital coverage (Social Security Administration, 1998b). Skilled nursing facility placement is covered if the placement occurs within 30 days of hospital discharge and is considered medically necessary (Noridian Mutual Insurance, 1999).

"Part B" Medicare services as mentioned earlier must be secured through payment of a monthly insurance premium by the beneficiary. Eligible beneficiaries include both resident citizens and some aliens over age 65 years. Those who receive "Part A" benefits due to disability are also eligible for Supplemental Medical Insurance, or "Part B" coverage.

In recent years, leading up to the new millennium, Medicare service providers including institutions have been certified under a variety of managed care programs. These services include types of services, as part of a package, which are not traditionally offered. Services such as preventative care may be included. However, provider facilities and providers are restricted in some ways.

\section{The Need for Medicare}

According to one source, during the early 1960's only about half of older Americans had any health insurance compared to $75 \%$ of all of those under 65 . Some were reported to have sought private coverage and were denied on the basis of age or pre-existing conditions. Others had not been able to afford it (National Academy On Aging, 1995).

Medicare was originally proposed as a mechanism to bring affordable coverage to the underinsured and uninsurable aging population. Disabled individuals were also included. Enhancements to the original entitlement program and additions to the original constituency have acted as a health care economic safety net for families, in addition to the elderly. For example, one estimate in 1994 indicates that Medicare was already 
providing coverage and services to an estimated 36 million beneficiaries (National Academy On Aging, 1995). The actual numbers of people positively affected by the program may exceed the mandate of Medicare.

\section{The Effect of Changing Technology and Health Service Delivery Needs}

For the 35 years of the last millennium that Medicare was available, the numbers of services available, populations eligible to receive services and mechanisms needed for accountability and cost control have responded to periods of conflict and uncertainty. This is even truer for the first few years of the new millennium. During the 1960's in a period of relative optimism and idealism, Medicare was enacted as part of a plan to support "the great society" under the Johnson administration. There were few initial changes other than to improve the reimbursement structure for physicians, outpatient care, and the inclusion of some allied health services such as physical therapy, chiropractics, and speech pathologists through the end of the Viet Nam conflict, with the notable exceptions of extending coverage to the disabled under age 65 and to provide coverage for those with end stage renal disease. However, following the oil and gasoline shortages of the early seventies, and the subsequent decrease in mobility of the automobile driving population, there were efforts to extend rural health clinic services and increase reimbursement schedules for home health related care.

Then, in the 1980's under the Reagan administration there were a number of service additions that included public health initiatives for vaccinations following the Swine flu reoccurrence anxiety of the late 1970's. Additionally, with increasing awareness of human immunosuppressive virus (HIV), policy makers passed legislation that provided coverage and services, for blood related pathogens such as Hepatitis-B vaccine and clotting factor coverage for hemophiliacs. First legislation providing benefits related to immunosuppressive drug therapy also emerged late into the decade.

However, during the Reagan era of the 1980's, and during a period of relative conflict and uncertainty that included an economic recession, and dramatically increased defense budget spending, additional legislation relative to cost containment efforts of rising health care costs emerged. These included Medicare coverage for hospice care and the inclusion of occupational therapists and clinical social workers as more cost efficient outpatient service care providers for a number of health and mental health services. Capitated health coverage service plans began to emerge in the delivery of care for health maintenance organizations (HMO's) and various prospective payment organizations (PPO's), and began to be debated as cost savings options for the public Medicare system.

Yet, in the 1990's, during a period of relative prosperity Medicare had the most numerous program expansions while legislators became aware of the need to develop responses to fraud and abuses in billing and reimbursement and coupled with perceived abuses in the social welfare economic supports system in general. Expansions included, the Catastrophic coverage act (P.L. 100-360), the Health Insurance Portability and Accountability Act of 1996 and Mental Health Parity Act of 1996, as well as provisions of the Balanced Budget Act of 1997, the Medicare, Medicaid, and SCHIP Balanced Budget Refinement Act of 1999, the Ticket to Work and Work Incentives Improvement Act of 1999 and the Benefits Improvement and Protection Act of 2000 .

\section{Health Care Crises of the Later Quarter of the 20th Century}

A study of the contribution of demographics to the Medicare financing problem raised concerns that delayed eligibility may not be sufficient to solve growing service delivery problems. The McKusick study 
reported that the Medicare financial burden is expected to double in the next 75 years relative to earnings. Moreover, persons born in 1946 would reach age 65 in 2011, and it is estimated that Medicare enrollment, at $15 \%$ of the population in the late 1990's, would increase to $25 \%$ by 2073. During this same period, the 20 to 64 years old work force would decline from $59 \%$ of the population to $55 \%$. The actual ratio of older population to working age population would change from $20 \%$ to $40 \%$. Medicare costs per person are reportedly expected to rise $35 \%$ by 2023 and up to $83 \%$ by 2073. Mortality is expected to decline, as fertility remains stable, or increase and immigration rates steadily contribute to the population (McKusick, 1999). However, projections were not fixed and may be affected by numerous unforeseen contingencies beyond 20 years.

In response to these concerns, there were a number of research inquiries reported in the literature that have addressed the utilization patterns of service provision as well as the costs of deciding to retire under Medicare coverage in the past Millennium and the economic costs of attempting to implement cost containment for Medicare coverage To this end they were instructive in attempting to understand the effect of changes and/or reform to the Medicare program in response to conflict and uncertainty, as well as to understand the affect these changes might have with respect to the changing demographic landscape of the United States in the new Millennium.

\section{Health Care Utilization}

For example, several sources provided information relative to understanding Medicare and health care utilization patterns late in the last Millennium. These demographic and research projections covered a range of utilization issues including types of coverage, family concerns, and minority utilization. A 1992 study attempted to examine three factors of health care utilization using the perspective of patient populations of young-old (65 to 74 years) and old-old (over 75 years) consumers. The study included the selection of a random sample of 804 enrollees of Medicare Part B. The investigation attempted to assess the adequacy of a behavioral model (Anderson's Behavioral Model) by employing a structural modeling approach. The predictors of health care utilization examined were predisposing health factors, enabling factors, and need factors of the two aged groups. The two measures of health care utilization in the study were number of nights spent in a hospital in the previous six months and number of physician office visits annually. Survey data from the sample were linked with existing archival insurance data for analysis. Findings demonstrated a moderate model fit for both populations. Need appeared to be the strongest direct positive influence on utilization. Utilization also increased with age. The authors noted that separate literature supported mental health status as a predictor of utilization, an observation that was not included in this study (Jewett, Hibbard, \& Weeks, 1991).

Another health service utilization investigation late into the last Millennium (Gibbons \& Wilcox-Gok, 1998) used a statistical multivariate probit analysis for multiple response variables as applied to a sample of 4,658 persons over age 65 on Medicare. The study evaluated the relationship between health insurance coverage and health service utilization. Response variables included: 1) medical provider visits, 2) hospital outpatient visits, 3) emergency room visits, 4) hospital inpatient stay, and 5) home health care visits. Separately types of supplemental insurance were categorized as either: 1) Medicaid, 2) private insurance, and 3) employer purchased private insurance. A number of demographic covariates were also included such as sex, age, race, marital status, education, income, urban location, and health status.

The study revealed a strong positive association between Medicaid and the utilization of all services. Other findings include: that income is negatively related to hospitalization, reporting of health status as excellent is 
negatively associated with utilization of all types of health services, and that the greatest correlation between services utilization is defined by two factors: 1) emergency room, hospital, and home health care service use, and 2) medical provider and outpatient service use.

The study also noted an increased probability of emergency room only use for Medicare only enrollees relative to Medicare enrollees with private insurance. This was also the case for Medicare plus Medicaid coverage. Medicare enrollees relative to enrollees with private insurance, tended to differ in use of outpatient treatment only for the Medicare only group, and increased use of home health care only or in combination with other services for the Medicare + Medicaid group (Gibbons \& Wilcox-Gok, 1998). Prediction aspects of Medicare utilization patterns based on this research form the last Millennium may not be limited to the existence of health factors, need, and type of coverage. Family and minority considerations are also important factors in utilization patterns.

Medicare is of benefit to families in addition to the elderly and disabled. According to one reporting source, in 1998 there were 70.9 million or $69.1 \%$ family, and 31.6 million or 30.9\% non-family households in the United States. Fewer than half of these households or $49 \%$ had children under age 18 years living at home. About $14.4 \%$ had children above age 18 residing at home. People living alone accounted for more than $82 \%$ of non-family households (Casper \& Bryson, 1998). Family households were estimated to represent approximately one third of the United States population of 269,094,000 (United States Census Bureau, 1998b). Health concerns of persons eligible for Medicare were expected to be distributed within these families to some proportion as would be anticipated within the general population.

The Federal Medicare program had provided subsidized health insurance for one in every seven Americans by the later years of the last Millennium. However, a larger number of these had been rural residents (Frenzen, 1997). Previously women have represented almost 60\% of those covered by Medicare and received $54 \%$ of all Social Security benefits (Erhenreich \& Piven, 1984). Payments of Social Security have been reported as less than those paid to males. During the implementation and revisions of Medicare, family households and children have been represented to some degree as indirect and direct beneficiaries of Medicare.

Another government source (United States Census Bureau, 1998b) revealed that 66,685,000 persons or $24.8 \%$ of the population, and $16,800,000$ children or $23.4 \%$ of children received some form of government sponsored health insurance, with an estimated 395,000 or 6\% of all children receiving Medicare insurance coverage specifically by the end of the Millennium. An estimated 217,000 or 1.5\% of these Medicare recipient children were considered poor (United States Census Bureau, 1998c). Children, and thus their families, are well represented as Medicare beneficiaries. However, utilization patterns appeared to occur differently for minority portions of the population as compared to families in general.

An examination of the effects of proposals to replace premiums with tax based financing had focused on how costs are distributed among families by income, race, and ethnicity (Rasell \& Bernstein, 1995). Minorities for the study were limited to Blacks and Hispanics only. Data on premiums and out of pocket expenditures from a 1987 National Medical Expenditure Survey (NMES) were reviewed for the study. Income tax rates from 1993 were matched to filing units in NMES using a weighted "hotdeck" technique. The 1987 expenditures in the data were aged to 1992 values. Some additional statistical adjustments with respect to income components were also performed. Results indicated that in 1992 white families average health care spending was \$3,735 greater than average health care spending by minority families. A high level of spending among lower income families occurred even though these families had high levels of being uninsured. Notably, at incomes below 
\$76, 260 minorities spend less than whites. Among families with public insurance, minority families were found to spend $13 \%$ less than white families. A simulation of universal health insurance coverage demonstrated that families in the lowest income quintile would pay a greater portion of cost than the highest quintile, if the coverage had been paid through a personal income tax. On the other hand, when premiums were paid through payroll tax, the per incidence premium is fairly flat (Rasell \& Bernstein, 1995).

Other available research from the last Millennium suggested differences in Medicare health care utilization rates among minority groups, in part due to cultural differences (Gordon, 1995). Reasons reviewed include continuity-of-care requirements, and criteria entailing the availability of primary care providers. African Americans are reported to distrust white service providers, a situation that causes some limitations. Hispanics, based on immigrant and other status, are less likely to have primary care providers and rely on other support systems.

\section{Medicare: Costs or Cost Savings}

Given these last Millennium utilization patterns and the emerging demographic crises, concerns over costs and cost savings are vital to balancing needs and expenditures A descriptive study of hospitals and the provision of "pro-bono" or uncompensated care for the poor, under recent changes in market conditions of the insurance industry, was undertaken and completed. The study noted that the lack of a universal entitlement system in the United States means that the health care system has relied on charitable care by medical providers to serve 40.6 million uninsured people. The study notes that uncompensated care delivered by all nonfederal community hospitals in the United States grew from \$6.1 billion in 1983 to $\$ 17.5$ billion in 1995 (Mann, Melnick, Bamezai, \& Zwaniger, 1997). Uncompensated care per insured person however, declined due to growing numbers of uninsured persons, even though uncompensated care as a portion of hospital expense remained stable from 1989 to 1993. Interestingly, the hospitals reporting the lowest gains in Medicare provided uncompensated care in similar proportions as in 1983. Medicare fiscal pressure is thought to have played a role, as hospitals less pressured by Medicare tend to have greater growth in uncompensated care. Changes in Medicaid as primary or supplemental insurance also increased the rate of uncompensated care by providers. However, HMO penetration within the same type of hospital market structure resulted in a lowering of the provision of uncompensated care when controlling for hospital size, and with the effect stronger in competitive markets (Mann et al., 1997).

The costs associated with post-acute care provided by skilled nursing facilities (SNF) and home health agencies (HHA's) were also becoming of increasing concern especially since affected by provisions of the 1997 Balanced Budget Act. The rise in post-acute care is thought to have occurred since the implementation of the Medicare Prospective Payment System (PPS) and Hospital Diagnostic Related Group (DRG) criteria for discharge. A current study analyzed data from a nationally representative sample of Medicare enrollees $(\mathrm{N}=$ $1,195)$ to extend previous research. The study proposes models of the likelihood of any individual's use of post-acute care, and a subsequent likelihood of choosing a skilled nursing facility over home health care. The study included personal characteristic variables, and market area and policy related variables. The study relied on binary dependent variables, which were analyzed through a multivariate analysis. An interactional analysis however found "few situations where personal characteristics had different effects when the intensity of supply differed". The findings indicated that for the total sample of people who had a hospital stay, that $63 \%$ had no post-acute services, that $13 \%$ had only SNF stays, and that 22\% had only HHA care, with $1.6 \%$ having both. 
For the total sample, Medicare payments averaged $\$ 4,950$ with a standard deviation of the distribution of payments being $\$ 7,105$. Average payments between patients in SNF's and HHA's differed by more than $\$ 1,000$ with SNF payments being larger. However, changes in one aspect of the post-acute care system are considered likely to affect other areas (Liu, Wissoker, \& Rimes, 1998).

A review of earlier research from the last Millennium on End Stage Renal Disease (ESRD) related that forestalling death from failed kidneys represents the 20th century's only example of vital organ replacement on a large scale. The review reported that "more than 500,000 people with ESRD are alive today as a product of research and teachings by nephrologists and transplant surgeons (Friedman, 1996). Surprisingly, ESRD was not included in Medicare until 1972. However, Medicare disbursements exceeded $\$ 180$ billion in 1993. The cost of Medicare reimbursement for ESRD has increased 10.5\% annually between 1991 and 1993 at nearly twice the rate of private health insurance. The author states that on a per patient basis, ESRD is the most expensive single kidney or urologic disorder billed to Medicare. With respect to incidence the study reports that in 1992, more than 205,000 patients were treated for ESRD in the United States with an unadjusted acceptance rate of 212 per million and a point prevalence rate on December 31, 1992 of 794 per million (Friedman, 1996).

Increasing rates of utilization and the high costs of specialty care in the last Millennium led some researchers to examine systemic cost saving strategies such as changes in distribution of some types of care. Multiple service delivery systems as compared to specialty service systems have been analyzed with respect to cost savings. The decision to retire and the effect on Medicare and other costs during periods of uncertainty have also been evaluated.

\section{Medicare: Cost Risks and the Decision to Retire}

An empirical analysis late in the last Millennium was undertaken to determine how Medicare, as part of the U.S. Social Security system, affects the retirement behavior and available labor supply of older males, considering incomplete markets for loans, annuities, and health insurance (Rust \& Phelan, 1997). The study utilized a sub-sample of 2,599 men for a total of 7,574 person-year observations. The study hypothesized a dynamic programming model (DP) to explain and estimate the joint labor supply and the decision to accept Social Security retirement and Medicare under specified market conditions. The model was able to generate a set of economic predictions of the dynamics of retirement behavior. The model accounted for retirement distribution at ages 62 and 65. Authors noted that a combination of risk aversion and the distribution of health care expenditures suggested a security value for members of the sample to remain employed until eligible for Medicare at age 65 (Rust \& Phelan, 1997).

Data from the 1987 National Medical Expenditure Survey (NMES) had been analyzed in another study to determine if Medicare supplemental insurance demand is related to attitudes directed toward avoiding costs of medical care and reducing economic risk (Vistnes \& Banthin, 1997). Attitudes were found to significantly influence beneficiaries decisions to avoid out of pocket expense and purchase supplemental insurance. Decisions to purchase or not purchase supplemental insurance and avoid risk were affected by attitude toward medical care, as well as, self-reported health measures, education and asset income. Other analysis efforts have investigated the costs versus cost savings related to services provided at the end of life and the possible economic implications during times of economic uncertainty.

\section{Cost Savings at the End of Life}

One research review of earlier studies that involved randomized trials to determine if claims that hospice 
care and advanced directives actually save on the costs of medical care at the end of life (Emanuel, 1996). The ability of Medicare to develop cost savings methods at the end of life could well affect the viability of the program during times of economic uncertainty given the emerging demographic changes in the geriatric population. To respond to these issues a separate national survey indicated that there were an estimated 2.5 million current patients and as many as 8.2 million discharges from 13,500 home health and hospice care agencies during 1996 (Centers for Disease Control, 1998). Medical care at the end of life was reported to consume $27 \%$ of the Medicare budget and $10 \%$ to $12 \%$ of the total national healthcare budget. The existing data suggested that hospice care and advanced directives can save from $25 \%$ to $40 \%$ of healthcare costs in the last month of life at that time (Emanuel, 1996).

A separate extensive literature review on the cost of illness at the end of life, differed with the previous study. The review found that hospice care and advance directives were unlikely to have a major impact on the costs of dying, except possibly for patients having executed an advance directive before admission to a hospital. The grant funded investigation also concluded the hypothesis could not be supported, which proposed that it was the high cost of high technology treatment of patients who died that had driven up the costs of dying. Elderly decedents were found to account for a disproportionate share of total Medicare cost, but the cost had actually remained constant at $27 \%$ to $30 \%$ of the total Medicare budget through the previous decade. Decedents in the 65 to 74 years of age range Medicare costs were $74 \%$ higher than decedents age 90 or over. About 73,000 decedents or under 5\% had high costs for the year 1988 using per capita payments of \$40,000 a year as a high cost threshold (Scitovsky, 1994).

\section{The Cost of Controlling Costs}

A Medicare proposal in the last Millennium attempted to project some of the future benefit needs for Medicare beneficiaries based on what was then known about the growing geriatric population. The tendency of the American population to live longer has meant that management of multiple chronic disorders has become a challenge for geriatric service providers. Preserving function has become a health requirement. Benefits are suggested which would maintain functioning into later years. For instance hearing loss affects over $40 \%$ of those over age 65 and is not covered currently by Medicare. More than $90 \%$ of those over age 65 had one or more chronic health conditions. Further, of the 31.4 million Americans at this age or older who reported income in $1997,79 \%$ reported income of less than $\$ 25,000$ with $37 \%$ reporting income less than $\$ 10,000$. Health costs are contributing to impoverishment. Efforts to control costs through Managed Care options for seniors have been inconsistent with some Managed Care entities having withdrawn from Medicare due to reported financial losses (Cassel et al., 1999).

A separate research inquiry attempted to analyze patterns of outpatient drug dispensing rates and costs, which are the focus of concern in the new Millennium, by the levels of cost sharing per dispense for elderly enrollees in a Managed Care program. The research used data from three national data sets to include enrollment history records, group benefit history, and outpatient drug dispense records $(\mathrm{N}=129,874)$. Three dependent variables were analyzed. Analysis utilized regression models to include: the probability that an enrollee is dispensed a drug from the Managed Care outpatient pharmacy, per month number of dispenses given at least one dispense per enrollee, and the, per month, per enrollee costs of drugs dispensed given at least one dispense. Independent variables included age, gender, Medicare status, enrollment status, and outpatient benefit class per enrollee. Findings reported included the effect of no outpatient drug benefit is to decrease the 
probability of dispense by 33\% per enrollee per month, and the number of dispenses by $59 \%$ and increase per enrollee per month costs of drugs by $71 \%$ (Roblin, 1994). The research demonstrated the need for coverage of drug costs to mange chronic ailments. Medications are necessary to prevent loss of function and more expensive institutional forms of care.

\section{Medicare Reform: Who Benefited? Who Paid?}

There are a number of health successes attributable to Medicare benefits (Centers for Medicare and Medicaid Services, 2000). A review of some prior Millennium empirically based studies found cost rather than positive contributions to health as the focus of study. Expected fiscal constraints may require difficult choices concerning limiting benefits and who will carry the burden of costs over the next century.

A recent descriptive summary of the effect of The Balanced Budget Act of 1997 reported that the legislation would realize program savings of $\$ 150$ billion during the first 5 years. However, this savings was expected to postpone the depletion of the Medicare Hospital Insurance (HI) trust fund from 2001 until no longer than 2010 (Foster, 1998). This projection occurred prior to the current deficit.

A separate Medicare projection study attempted to use a research method known as "incidence analysis" to attempt to determine who will pay and who will benefit under proposed Medicare reform efforts in the last Millennium. Incidence analysis traced the overall impact of a given program policy on the financial or more general well being of various groups of people, with a full accounting of dollar values of costs and benefits for each group (McClellan \& Skinner, 1999). From the perspective of cohorts of persons born in 1925 or 1945 the benefits and burdens of Medicare have been shared differently.

For example, the first group paid for coverage about half of their working life, had the knowledge of long term insurance security to facilitate financial planning, a lower proportion of taxed income, and a greater number of younger persons contributing to the benefit program. For the later cohort, the entire working life is spent contributing, without certainty of health care coverage in old age, a higher proportion of taxed income results in a decreased standard of living in some ways, and a decreasing labor pool to contribute to the viability of the program. Proportional differences in real adjusted income for the later group were expected to result in a greater proportion of income-based mortality changes. This means that those supporting the health and welfare of an aging generation are making sacrifices that will diminish their own prospects of longevity and optimum health care. Additionally the later cohort will experience less redistribution from middle low-income groups to upper middle income-groups.

The popular notion that higher income groups will pay a higher portion of financing costs with similar coverage, as the fairest way to administer the program, is also questioned. Higher income cohorts enjoy better health and will likely live longer thus using a greater proportion of total benefits.

Another relatively recent research effort attempted to break out costs by categories in ways not usually reported in Medicare reports. Costs broken out were used to identify trends in funds to health care providers. Such information is considered vital for planning policy for Medicare cost control. The study undertaken by Welch published in 1998 determined that nearly $40 \%$ of payments to non-Perspective Payment services were made to rehabilitation hospitals. Further review determined that patients in skilled nursing facilities, who were no longer eligible for Part A (HI) after exhausting their benefits, were increasingly recipients of rehabilitation services. The study also revealed a number of relationships in payment to skilled nursing facilities, rehabilitative services, and home health services with programs based within hospitals using various "swing 
beds" approaches to provide services. Various outpatient services including imaging services, diagnostics and other procedures were also related to hospital services. The "dis-aggregation" analysis revealed that fiscal intermediaries for Medicare paid out $\$ 1.7$ billion through the Part B benefit to providers of rehabilitation services and that this expenditure had grown rapidly (Welch, 1998).

Sufficient empirical literature existed at the close of the last Millennium to demonstrate the heavy cost to society and to individuals of under funding the Medicare program. There are costs associated with delaying retirement, costs associated with not addressing adequately end of life care issues, costs of failing to address the prescription medication costs among the elderly, and to address the affect of cost containment efforts in times of uncertainty. Times of conflict are most certainly also times of uncertainty. The original need for Medicare; as expressed eloquently by President Johnson was, in part a way to aspire to achieve the great society in the last Millennium. A society of a well supported and well educated working population with the necessary economic assurances from the Federal government that the least able among them would have the health service delivery system, to care for their loved ones, infirmities as younger and more able members of the society set out an agenda to advance individual, and national achievements.

\section{The Medicare Transition to the New Millennium}

The new Millennium has not seen a resolution of conflict and uncertainty. Medicare is currently affected by a wave of tumult both politically and economically since the turn of the century marking the change in the Millennium. The United States has been deeply affected by the holocaust of September 11, 2001, as well as by the change in administrative geopolitical and social welfare philosophy of the Bush administration. The destruction of the world Trade Center in New York and the attack on the Pentagon in Washington D.C., have served to greatly contribute to concerns about the future of Medicare and to the capacity of the United States to finance a long term adequate level of health care coverage for its most needy citizens.

The last few years have seen a shift in spending to fight the war on terrorism including; the Development of a Department of Homeland Security, increases in security intelligence and defense spending and appropriations (nbc6.net, 2003), the War in Afghanistan, increasing tension with North Korea, the war in Iraq, military deployments in numerous locations to assist other governments fight terrorism and reduce conflict as in the recent deployment to Liberia. Simultaneously, a recession in the making prior to September $11^{\text {th }}$ has intensified to create a set of conditions that have rapidly eroded a formerly perceived budgetary surplus to a verified deficit economy that has undermined both federal and state governments capacity to respond to the social needs of their respective populations. The national deficit is expected to reach record highs in 2003 and 2004. These deficits began in 2001 in response terrorist attacks in 2001 according to White House spokesman Ari Fleisher (nbc6.net, 2003). These economic conditions resultant from conflict and uncertainty are taking a toll on the Medicare program. Out-of-pocket costs for Medicare beneficiaries enrolled in health plans have doubled since 1999, to an average of $\$ 1,964$ in 2003. People in poor health have much higher costs, averaging $\$ 5,305$ a year (Abelson, 2003). $\$ 400$ billion is currently being sought by lawmakers designated to be spent over a 10 year period to overhaul Medicare. At his time, in 2003, the Medicare program provides health care coverage for 40 million Americans. Total enrollment is expected to reach 77 million by 2031, when the baby boom generation becomes fully enrolled.

The Public Health Security and Bioterrorism Response Act of 2002 (“The Act”) (Public Law 107-188) included changes to certain provisions of the Social Security Act governing the Medicare + Choice program. At 
this time, the enrollment lock-in period has been delayed for three years meaning that there are fewer viable Medicare + Choice contractors available due to the current economic uncertainty. Efforts to stimulate the economy amid current world conflict have not been fully effective. Tax cuts promoted by the Bush administration as economic stimulus following deficits expected actually expected to add up to $\$ 1.3$ trillion, but may not have the intended effect of restoring economic certainty (Abelson, 2003).

\section{Implications for Millenial Social Work and the Future}

Social Workers are faced with difficult choices in promoting and meeting public health care needs. At risk is the real possibility of diminishing benefits and loss of nearly 35 years of health care progress. Maintaining current benefits however, may result in a reduced standard of living for much of the current and next generation and eventual loss of benefits. The consequences of failing to fund, or severely reducing funding of the Medicare program would also be catastrophic.

\section{References}

Abelson, R. (2003). Report on medicare legislation raises concern on costs. New York Times, August 11.

Casper, L. M., \& Bryson, K. (1998). Current population reports, population characteristics, household and family characteristics: March 1998 (Update) (pp. 20-515). U.S. Department of Commerce Economics and Statistics Administration.

Cassel, C. K., Besdine, R. W., \& Siegel, L. C. (1999). Restructuring medicare for the next century: What will beneficiaries really need? Health Affairs, 18(1), 118-131.

Centers for Medicare and Medicaid Services. (2000). History of medicare and medicaid [Available: online] https://cms.hhs.gov/about/history/ssachr.asp. Accessed August 22, 2003.

Centers for Disease Control. (1998, December 8). Abstract and result from the 1996 national home and hospice care survey [On-line]. Available: http://www.cdc.gov/nchswww/about/major/nhhcsd/nhhcdh.htm

Emanuel, E. J. (1996). Cost savings at the end of life: What do the data show? Journal of the American Medical Association, 275(24), 1907-1914.

Erhenreich, B., \& Piven, F. F. (1984). The feminization of poverty. Dissent, 31(2), 162-170.

Foster, R. (1998). The financial status of medicare. Public Health Reports, 113(March/April), 110-117.

Frenzen, P. D. (1997). Issues in rural health: How will measures to control medicare spending affect rural communities? Agriculture Information Bulletin No. 734. Washington D.C.: Rural Economy Division, Economic Research Service, U.S. Department of Agriculture.

Friedman, E. M. (1996). End stage renal disease: An American success story. Journal of the American Medical Association, 275(14), 1118-1122.

Gibbons, R. D., \& Wilcox-Gok, V. (1998). Health service utilization and insurance coverage: A multivariate probit analysis. Journal of the American Statistical Association, 93(441), 63-72.

Gordon, A. K. (1995). Deterrents to access and service for blacks and Hispanics; the medicare hospice benefit, healthcare utilization, and cultural barriers. The Hospice Journal, 10(2), 65-83.

Jewett, J. J., Hibbard, J. H., \& Weeks, E. C. (1991). Predictors of health care utilization for the young-old and the old-old: A structural modeling approach. Behavior, Health, and Aging, 2(1), 29-41.

Liu, K., Wissoker, D., \& Rimes, C. (1998). Determinants and costs of medicare post-acute care provided by SNF's and HHA's. Inquiry, 35(Spring 1998), 49-61.

Mann, J. M., Melnick, G. A., Bamezai, A., \& Zwaniger, J. (1997). A profile of uncompensated hospital care, 1983-1995. Health Affairs, 16(4), 223-232.

McClellan, M., \& Skinner, J. (1999). Medicare reform: Who pays and who benefits. Health Affairs, 18(1), 48-62.

McKusick, D. M. (1999). Demographic issues in medicare reform. Health Affairs, 18(1), 194-207.

nbc6.net (2003). Record deficits seen in Bush's \$2.23 trillion budget [Available: online] https://nbc6.net/money/1953414/detail.html. Accessed August 22, 2003.

National Academy on Aging. (1995). Facts on medicare: Hospital insurance and supplementary medical insurance. [On-line]. Available: http://www.epn.org/library/agmedi.htm 
National Center for Health Statistics, (1997). Advance data No. 289 (p. 3). Hyattsville Maryland: Public Health Service. [Online]. Available: http://www.cdc.gov/nchswww/

National Center for Health Statistics. (1998). Abstract and result from the 1996 national home and hospice care survey. [Online]. Available: http://www.cdc.gov/nchswww/about/major/nhhcsd/nhhgdh.htm

Noridian Mutual Insurance, Government Services. (1999). Medicare: A brief history and summary. [On-line]. Available: http://www.bcbsnd.com/medweb/history.html

Rasell, E., \& Bernstein, J. (1995). Implications of health and welfare reform for the black community: An assessment of health-care expenditures within and across racial and ethnic groups. AEA Papers and Proceedings, 85(2), 127-131.

Roblin, D. W. (1994). Drug dispense rates and costs by benefit type: An analysis of purchase patterns by the elderly in a prepaid group practice HMO. Paper presented at the 1994 ASHR Annual Meeting: Research in Health Economics and Health Finances, San Diego, California.

Rust, J., \& Phelan, C. (1997). How social security and medicare affect retirement behavior in a world of incomplete markets. Econometrics, 65(4), 781-831.

Scitovsky, A. (1994). The high cost of dying revisited. The Milbank Quarterly, 72(4), 561-591.

Scott, J. S. (1996). The new health insurance act: A powerful weapon for fighting fraud and abuse. Healthcare Financial Management, November, 224-226.

Social Security Administration, Office of the Chief Actuary. (1998a). History of the provisions of old age, survivors, and disability insurance 1935-1996. [On-line]. Available: http://www.ssa.gov/OACT/HOP/hopiii.htm Accessed April 16, 2000.

Social Security Administration, Office of the Chief Actuary. (1998b). Legislation affecting social security and medicare programs. [On-line]. Available: http://www. ssa.gov/OACT/HOP/hopiv.htm. Accessed: April 16, 2000.

United States Census Bureau. (1998a)._Current population survey (Vol. March,). [On-line]. Available: http://www.census.gov/hhes/hlthins/hlthin97/

United States Census Bureau. (1998b). Health insurance coverage: 1997-Table 1.

U.S. Census Bureau, March 1998 Current Population Survey. [On-line]. Available: http://www.census.gov/hhes/hlthins/97/hi97t1.html

United States Census Bureau. (1998c). Health insurance coverage: 1997-Table 6.

U.S. Census Bureau, March 1998 Current Population Survey. [On-line]. Available: http://www.census.gov/hhes/hlthins/97hi97t6.html

Vistnes, J. P., \& Banthin, J. S. (1997, Winter). The demand for medicare supplemental insurance benefits: The role of attitudes toward medical care and risk._Medicare Supplemental Insurance Inquiry, 34, 311-324. 